\title{
MANUFACTURE OF NANOSIZED APATITE COATINGS ON TITANIUM WITH DIFFERENT SURFACE TREATMENTS USING A SUPERSATURATED CALCIFICATION SOLUTION
}

\author{
Adrian Paz Ramos, Gabriel O. Ybarrab, Leonardo M. Pazos', María B. Parodi', Laura Rodríguez, Mónica López \\ Hernández ${ }^{\mathfrak{c}}$ and Jesús E. González Ruíz ${ }^{\mathrm{d}, *}$ \\ aDepartment of Chemistry, Université de Montréal, Succursale Centre-Ville, Montréal - Québec, Canada \\ bNational Institute of Industrial Technology, General Paz Avenue 5445, San Martin - Buenos Aires, Argentina \\ 'National Center for Scientific Research, 25 Avenue and 158 ${ }^{\text {st }}, 11300$ - Havana, Cuba. \\ ${ }^{\mathrm{d} D e p a r t m e n t}$ of Ceramic and Metallic Materials, Biomaterials Center, Universidad Avenue and G, 10400 - Havana, Cuba.
}

Recebido em 16/02/2016, aceito em 24/06/2016, publicado na web em 30/08/2016

\begin{abstract}
The biomimetic method is used for the deposition of calcium phosphate coatings $(\mathrm{Ca}-\mathrm{P})$ on the surface of different biomaterials. However, the application of this method requires long exposure times in order to obtain a suitable layer thickness for its use in medical devices. In this paper, we present a fast approach to obtain apatite coatings on titanium, using a combination of supersaturated calcification solution (SCS) with chemical modification of the titanium surface. Also, it was evaluated the effect of four different surface treatments on the apatite deposition rate. Commercially pure titanium plates were activated by chemical or thermochemical treatments. Then, the activated samples were immersed in a solution with high content of calcium and phosphate ions at $37{ }^{\circ} \mathrm{C}$ for $24 \mathrm{~h}$, mimicking the physiological conditions. The coatings were studied by Fourier transform infrared spectroscopy (FTIR), X-ray diffraction (XRD), scanning electron microscopy (SEM) and energy dispersive X-ray spectroscopy (EDX). The use of SCS solutions allowed the formation of crystalline hydroxyapatite coatings within a period of $24 \mathrm{~h}$ with a thickness between 1 and $5.3 \mu \mathrm{m}$. Besides, precipitates of hydroxyapatite nanoparticles with a globular configuration, forming aggregates with submicrometer size, were found in SCS solutions.
\end{abstract}

Keywords: Coatings, thin films, biomaterials, ceramics.

\section{INTRODUCTION}

Titanium and its alloys are among the most widely used metallic materials in the manufacture of implants due to its excellent mechanical properties, low specific weight, high corrosion resistance and excellent biocompatibility. ${ }^{1-6}$ However, its osseointegration is slow, ${ }^{6}$ affecting the life quality of patients. Several works have shown that changes in the topography, surface energy and phase composition on the titanium surface can significantly influence its rate of osseointegration..$^{711}$ The biomimetic method has been widely used in the past decades because it is possible to obtain coatings with a phase composition analogous to the inorganic component of the bone. ${ }^{12}$ In addition, this technique does not require special facilities and high temperatures for its implementation, it enables the treatment of porous surfaces and also the possibility to incorporate bioactive agents and proteins. ${ }^{13-15}$ Unfortunately, the length of the processes has limited the extension of this method to the treatment of dental implants and prostheses made of titanium and its alloys. ${ }^{16}$

The behavior of calcium phosphate coatings in vivo depends largely on its crystallinity, elemental and phase composition. ${ }^{17,18}$ The biomimetic method allows to modify those parameters from the ionic composition of the solution, the ion content of the precursor employed and their relationship. Several works described the formation of apatite coatings, which are completely or partially constituted by octacalcium phosphate (OCP), dicalcium phosphate (DCP), hydroxyapatite (HA), hydroxycarbonate apatite (HCA) or carbonated apatite (CA). ${ }^{19-24}$ Also, calcium phosphate coatings with different degree of crystallinity were reported. ${ }^{25}$

Among the alternatives to shorten the exposure time are the use of solutions with high content of calcium and phosphate ions

*e-mail: jesus.gonzalez@biomat.uh.cu and the incorporation of magnesium salts into these solutions. ${ }^{19,26-28}$ Furthermore, it has been shown that the surface roughness, chemical composition and phases present in the surfaces can enhance the rate of apatite coating formation. Acid etching and their combination with heat treatments (thermochemical treatments) are used for the surface modification of titanium, because they modify its elemental and phase composition, but also the topography and wettability. ${ }^{29-31}$ In addition, this treatment improves the in vitro and in vivo behavior of titanium and its alloys. ${ }^{9,29,32}$ Within the chemical procedures used to activate the surface of titanium and its alloys are treatments that enhance the formation of oxides or hydroxides, ${ }^{30,31,33}$ and others which enable the formation of titanates (treatments in sodium hydroxide or calcium-ion solutions). ${ }^{16,34-36}$

The aim of this study is to determine the effect of four treatments of surface activation applied to the commercially pure titanium on the deposition of apatite coatings in a supersaturated calcification solution.

\section{EXPERIMENTAL}

\section{Sample preparation}

Twenty plates of commercially pure titanium $(\mathrm{Ti}-\mathrm{cp})$ of $15 \times$ $5 \times 1 \mathrm{~mm}$ in size were polished using silicon carbide $(\mathrm{SiC})$ paper of 120, 240, 400 and 600 grit. After polishing, the samples were cleaned in an ultrasonic bath with distilled water and then activated by four chemical and (or) thermochemical treatments (Table 1).

\section{Ca-P coating formation}

The reagent grade chemicals $\mathrm{CaCl}_{2}, \mathrm{NaH}_{2} \mathrm{PO}_{4}$ and $\mathrm{NaHCO}_{3}$ were successively dissolved in $500 \mathrm{~mL}$ distilled water to prepare a 
Table 1. Treatments used for the surface activation

\begin{tabular}{ll}
\hline Treatment & Treatment details \\
\hline Acid etching (AE) & $\begin{array}{l}\text { Acid etching in } \mathrm{HF} 2.75 \mathrm{M}-\mathrm{HNO}_{3} 3.94 \mathrm{M}, \mathrm{v} / \mathrm{v} 1: 1 \\
\text { at room temperature for } 2 \mathrm{~min} .\end{array}$ \\
Oxidation 1 (AEP) & $\begin{array}{l}\text { Acid etching + treatment in } \mathrm{H}_{2} \mathrm{O}_{2} 8.8 \mathrm{M}-\mathrm{HCl} 0.1 \mathrm{M} \\
\mathrm{v} / \mathrm{v} 1: 1 \text { at } 80{ }^{\circ} \mathrm{C} \text { for } 30 \mathrm{~min} .\end{array}$ \\
Oxidation 2 (AEPTT) & $\begin{array}{l}\text { Acid etching + oxidation 1 + thermochemical treat- } \\
\text { ment at } 400{ }^{\circ} \mathrm{C} \text { for } 1 \mathrm{~h} \text { in air. }\end{array}$ \\
Oxidation 3 (AEAT) & $\begin{array}{l}\text { Acid etching + treatment in } 10 \mathrm{M} \mathrm{NaOH} \text { at } 80{ }^{\circ} \mathrm{C} \\
\text { for 24 h. }\end{array}$ \\
\hline
\end{tabular}

supersaturated calcification solution (SCS). The masses of salts and ion concentrations of SCS were equal to those employed by Li et al. (Table 2). ${ }^{21}$ After the activation treatment, the titanium plates were tied with a cotton thread and immersed vertically into $500 \mathrm{~mL}$ of SCS solution at $37^{\circ} \mathrm{C}$ for $24 \mathrm{~h}$, with a stirring rate of $80 \mathrm{rev} \cdot \mathrm{min}^{-1}$. A Ti plate representing each surface treatment was immersed into the solution in each experimental run. After exposure, the samples were carefully washed with distilled water and dried at $60{ }^{\circ} \mathrm{C}$ for $2 \mathrm{~h}$. At the end of the deposition process, the solution was centrifuged and filtered. Finally, the precipitates were collected and dried at $60{ }^{\circ} \mathrm{C}$ for $2 \mathrm{~h}$. All experiments have been repeated at least 3 times in order to ensure the data reproducibility.

Table 2. Masses of salts and ion concentration in $500 \mathrm{~mL}$ of supersaturated calcification solution (SCS)

\begin{tabular}{|c|c|c|c|c|}
\hline \multicolumn{5}{|c|}{ Masses of salts $(\mathrm{mg})$ in $500 \mathrm{~mL}$ of SCS } \\
\hline & & & & $\mathrm{NaHCO}_{3}$ \\
\hline & & & & 63 \\
\hline \multicolumn{5}{|c|}{ Ion concentration (mM) } \\
\hline $\mathrm{Na}^{+}$ & $\mathrm{Ca}^{2+}$ & $\mathrm{Cl}^{-}$ & $\mathrm{H}_{2} \mathrm{PO}_{4}^{-}$ & $\mathrm{HCO}_{3}^{-}$ \\
\hline 4 & 10 & 20 & 2.5 & 1.5 \\
\hline
\end{tabular}

\section{Characterization}

The $\mathrm{pH}$ value was measured during the solutions preparation and at the coating process with a Pracitronic MV870 pHmeter. The functional groups of the coatings were determined by Fourier transformed infrared (FTIR) spectroscopy on a Nicolet Magna 550 Series II. Besides, the coatings were investigated using a Philips PW1730 X-ray diffractometer (XRD) with a $\mathrm{CuK} \alpha$ target. The phase identification was made using the PCPDFWIN database, v. 2.4 ICDD PDF-2/2003.

The size and morphology of the particles obtained in solution were characterized by transmission electron microscopy (TEM), in a Philips CM10 microscope, using an acceleration voltage of $80 \mathrm{kV}$. The dimensions of the particles were determined by digital image analysis using the software ImageJ.

The morphology of the coatings was characterized by scanning electron microscopy (SEM) using a Philips SEM 505 microscope for low magnification and a Zeiss microscope FESEM Supra 40 for increases greater than 5000x. In addition, it was identified their elemental composition using an energy dispersive X-ray spectroscopy (EDX) coupled to SEM. The statistical processing of results was performed in Statgraphics software, using a multi-sample comparison test (Multiple Range Tests) and analysis of variance (ANOVA).

\section{RESULTS AND DISCUSSION}

Figure 1 shows the behavior of the average $\mathrm{pH}$ value of the solution, which was characterized by four different stages. In the first stage (I in Figure 1), it was observed a significant increase in $\mathrm{pH}$ values up to a maximum at around one hour of exposure $(6.44 \pm$ $0.06)$. Subsequently, it was observed a rapid decrease in $\mathrm{pH}$ values of $5.8 \pm 0.06$, between 1.5 and $3 \mathrm{~h}$ (stage II, Figure 1). Then, between 3 and $5.5 \mathrm{~h}$, the values decreased slowly (stage III) and finally the reduction was even slower to reach a value of $5.58 \pm 0.09$ at $24 \mathrm{~h}$ (stage IV). It is important to notice that during stage II, it was observed the formation of precipitates, consisting of tiny white particles on the surface of the samples and in the solutions.

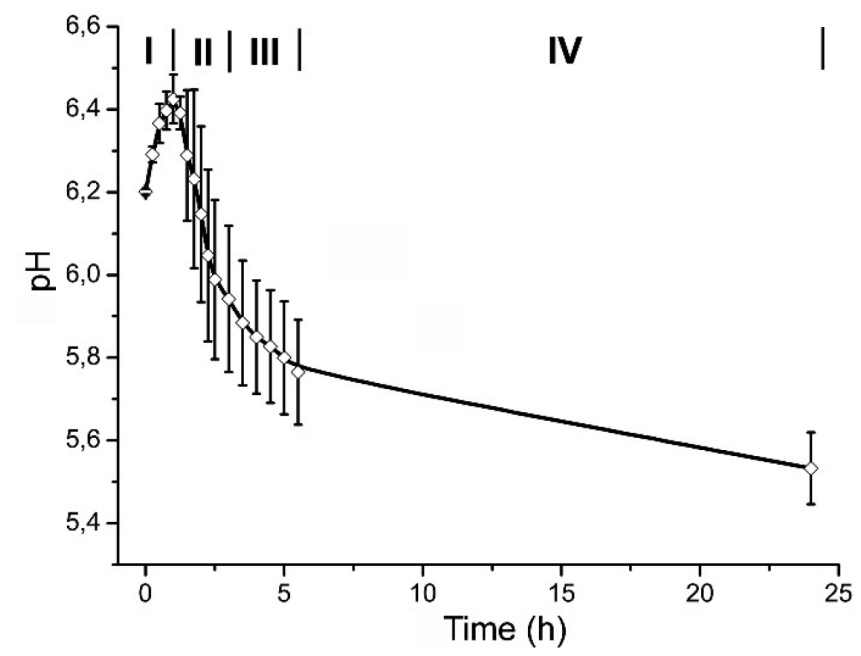

Figure 1. pH of the solution versus exposition time

The study by TEM of the particles formed in solution showed a globular configuration and an average diameter of $29 \pm 5 \mathrm{~nm}$ (Figure 2). In addition, the nanoparticles formed a cluster with irregular shape and size generally less than $1 \mu \mathrm{m}$ (Figure 2).

FTIR results of the precipitates showed the main groups of hydroxyapatite (Figure 3). At 1040 and $1091 \mathrm{~cm}^{-1}$ was observed the most important band of hydroxyapatite, the antisymmetric vibration of calcium phosphates $\mathrm{v}_{3}{ }^{\text {as }}\left(\mathrm{PO}_{4}{ }^{3-}\right)$. At $952 \mathrm{~cm}^{-1}$ was revealed the symmetrical vibration, while at 561 and $606 \mathrm{~cm}^{-1}$ was observed the antisymmetric vibration $\mathrm{v}_{4}^{\text {as }}\left(\mathrm{PO}_{4}^{3-}\right)$. Also, at $3400 \mathrm{~cm}^{-1}$ was observed a broad band of water, produced by the absorption of humidity by the samples during the deposition process. In addition, it was observed a band at $635 \mathrm{~cm}^{-1}$, corresponding to the out-of-plane bending $(\rho)$ of the structural $\mathrm{OH}^{-}$group and a signal located at $1643 \mathrm{~cm}^{-1}$, from water adsorption (Figure 3).

The morphology of the activated titanium surface using the four variants is presented in Figure 4 A, E, I and M. As a result of acid treatment, it was obtained a surface with several micropores, with size between 3 and $15 \mu \mathrm{m}$. Subsequent treatments in hydrogen peroxide and (or) thermochemical did not significantly affect the topography of the surfaces (Figure 4 E, I). On the samples with alkali treatment (AEAT) were observed not only the pores generated by acid etching (Figure $4 \mathrm{M}$ ), but also additional nanopores evenly distributed across the surface (not shown).

The topography of titanium samples after treatment in SCS showed significant variations (Figure $4 \mathrm{~B}, \mathrm{~F}, \mathrm{~J}$ and $\mathrm{N}$ ). The pores and ridges formed during the activation treatments disappeared in all cases. Higher-magnification micrographs of the samples soaked in SCS showed coatings with dense and microporous zones (Figure $4 \mathrm{C}, \mathrm{G}, \mathrm{O}, \mathrm{D}, \mathrm{H}$ and P). An exception of this behavior was observed in the samples under thermochemical treatment (AEPTT), in which a majority of dense coating was formed (Figure $4 \mathrm{~K}$ and L). This last coating was constituted by nanoparticles with a globular configuration, 

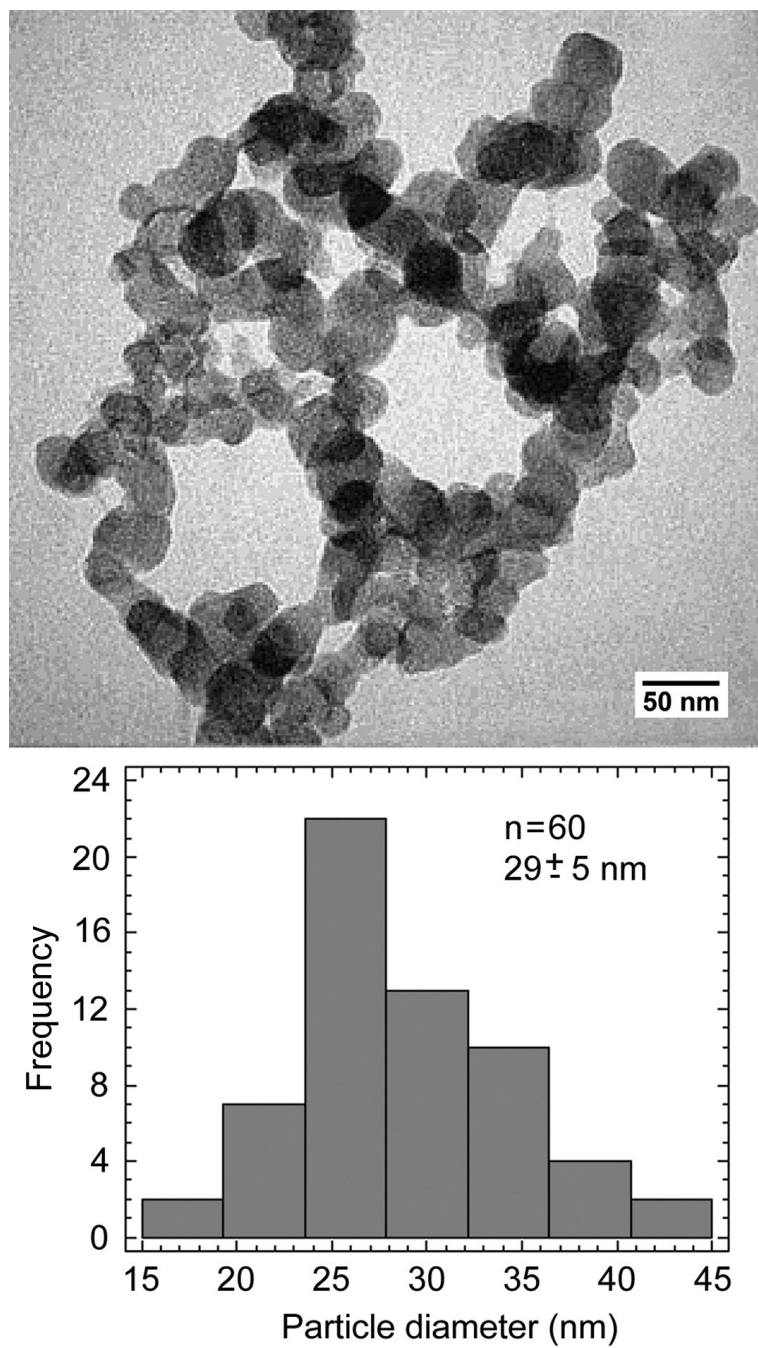

Figure 2. TEM image and particle size distribution of the precipitates formed in SCS solution

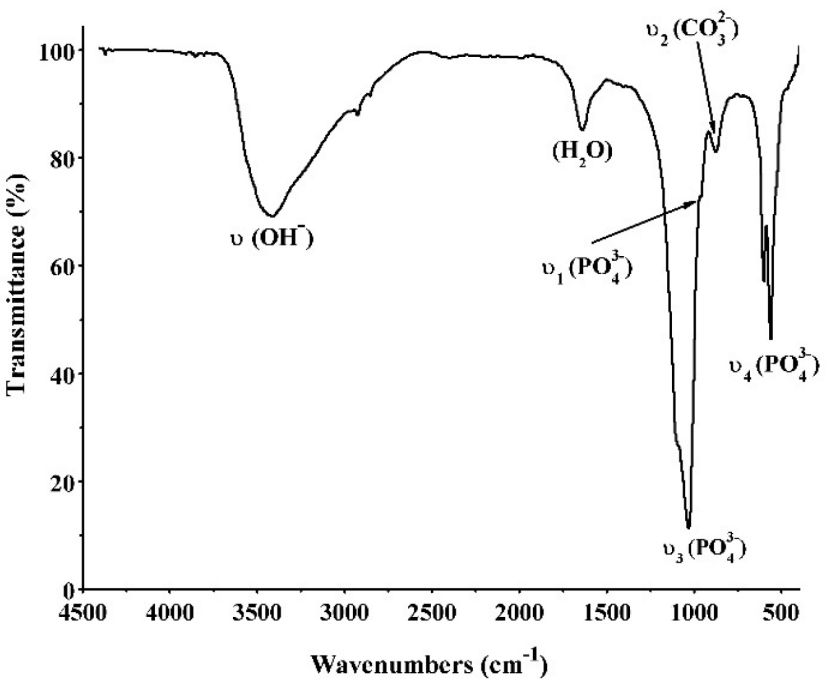

Figure 3. FTIR spectrum of the precipitates formed in SCS solution

with a size between 11 and $82 \mathrm{~nm}$ and an average diameter of $34 \pm 15$ $\mathrm{nm}$. In that area, it was observed that the nanoparticles formed some clusters with a maximum length of $245 \pm 126 \mathrm{~nm}$. Furthermore, it could be found some plate-like shape particles on the coating with a perpendicular orientation to the surface and a length of $170 \pm 84 \mathrm{~nm}$.
The samples activated by AE, AEP and AEAT variants exhibited a combination of dense and microporous zones (Figure 4 C, G, O, D, $\mathrm{H}$ and $\mathrm{P}$ ). Those microporous zones were constituted by several plate-like shape particles, oriented perpendicularly to the surfaces. The length of the particles changed depending on the activation treatment $(\mathrm{AE}=133 \pm 54 \mathrm{~nm}, \mathrm{AEP}=358 \pm 149 \mathrm{~nm}$ and $\mathrm{AEAT}=378 \pm 197$ $\mathrm{nm}$ ), while the maximum size of the pores was in the submicron scale.

The elemental composition analysis by EDX showed that the coatings are constituted of calcium, phosphorus, oxygen, and also revealed the titanium from the substrate (Figure 5). Additionally, in the samples activated by AEAT variant was observed a greater intensity in the characteristic peaks of calcium and phosphorus compared with the other samples (Figure 5). Besides, the spectra do not reveal the presence of other elements.

The FTIR spectra of the coatings showed the signals corresponding to hydroxyapatite (Figure 6). The comparison between the FTIR spectra of coating and precipitates shows that there is no difference on the presence and location of the signals, which indicates that the compositions of both materials are presumably the same.

The XRD patterns corroborate the formation of the apatite coatings. The reflection peaks with interplanar distances of 3.46 , $2.79,2.67$ and $1.84 \AA\left(2 \theta=25.74,32.11,33.77\right.$ and $\left.49.39^{\circ}\right)$ were assigned to crystalline apatite $\left(\mathrm{Ca}_{10}\left(\mathrm{PO}_{4}\right)_{6}(\mathrm{OH})_{2}\right)$ (Figure 7). Also, at the interplanar distances of $2.57,2.36$ and $2.25 \AA(2 \theta=34.97,38.20$ and $40.03^{\circ}$ ) the titanium substrate was revealed.

Cross-section micrographs of the deposits corroborate that all samples were uniformly coated and that the layer thicknesses were between 1 and $5.3 \mu \mathrm{m}$ (Figure 8 ). The greater coating thicknesses were obtained using both the AEPTT and AEAT treatments. In addition, it was observed that the greatest thicknesses are generally found in the porous areas, generated during the acid treatment (Figure 8).

The $\mathrm{pH}$ curves of the SCS solution have four well differentiated stages (Figure 1). The $\mathrm{pH}$ increase in the first stage is related to the reaction of $\mathrm{H}^{+}$ions with $\mathrm{HCO}_{3}{ }^{-}$(generated by the dissociation of $\mathrm{NaHCO}_{3}$ ), according to equation $1 .^{21}$ During this period, it must be generated some apatite nuclei, which enhances the film growth according to the mechanism described by Barrere et al. ${ }^{19}$ In the limit of stages 1 and 2, after reaching the maximum $\mathrm{pH}$ value, there is a sharp inflection in the curve (Figure 1). This phenomenon is caused by the combination of high ionic strength with a high $\mathrm{pH}$ value, which promotes the supersaturation of the solution. This causes a strong reaction between $\mathrm{Ca}^{2+}$ ions and $\mathrm{OH}^{-}$(equation 2) and the apatite precipitation in the solution and on the activated titanium surface. A similar behavior is reported when using solutions with an ionic concentration five times superior to the simulated body fluid (SBF x 5). ${ }^{19,25}$ In addition, the rapid consumption of $\mathrm{OH}^{-}$during stage 2 causes the rapid drop of $\mathrm{pH}$ values (Figure 1). At this stage Habibovic reported a significant increase in thickness of the calcium phosphate layer. ${ }^{20}$

$$
\begin{gathered}
\mathrm{H}^{+}+\mathrm{HCO}_{3}{ }^{-} \rightarrow \mathrm{CO}_{2}+\mathrm{H}_{2} \mathrm{O} \\
10 \mathrm{Ca}^{2+}+6 \mathrm{PO}_{4}{ }^{3-}+2 \mathrm{OH}^{-} \rightarrow \mathrm{Ca}_{10}\left(\mathrm{PO}_{4}\right)_{6}(\mathrm{OH})_{2}
\end{gathered}
$$

The inflection of the $\mathrm{pH}$ curve may be explained by the precipitation of HA, according to equation (2). Due to the decreased amount of $\mathrm{OH}^{-}$ions in the solution, a $\mathrm{pH}$ drop was observed. The tendency observed in stages 3 and 4 can be related to the film growth. In those stages the $\mathrm{pH}$ values decrease becomes slower until the end of the process. This behavior should be linked to the slow consumption of $\mathrm{Ca}^{2+}$ and $\mathrm{PO}_{4}{ }^{3-}$ ions in the solution as a result of the coating process and the formation of particles in the solution during the previous stages.

The approach employed allows the formation of hydroxyapatite nanoparticles in the solution and on the titanium surface activated 


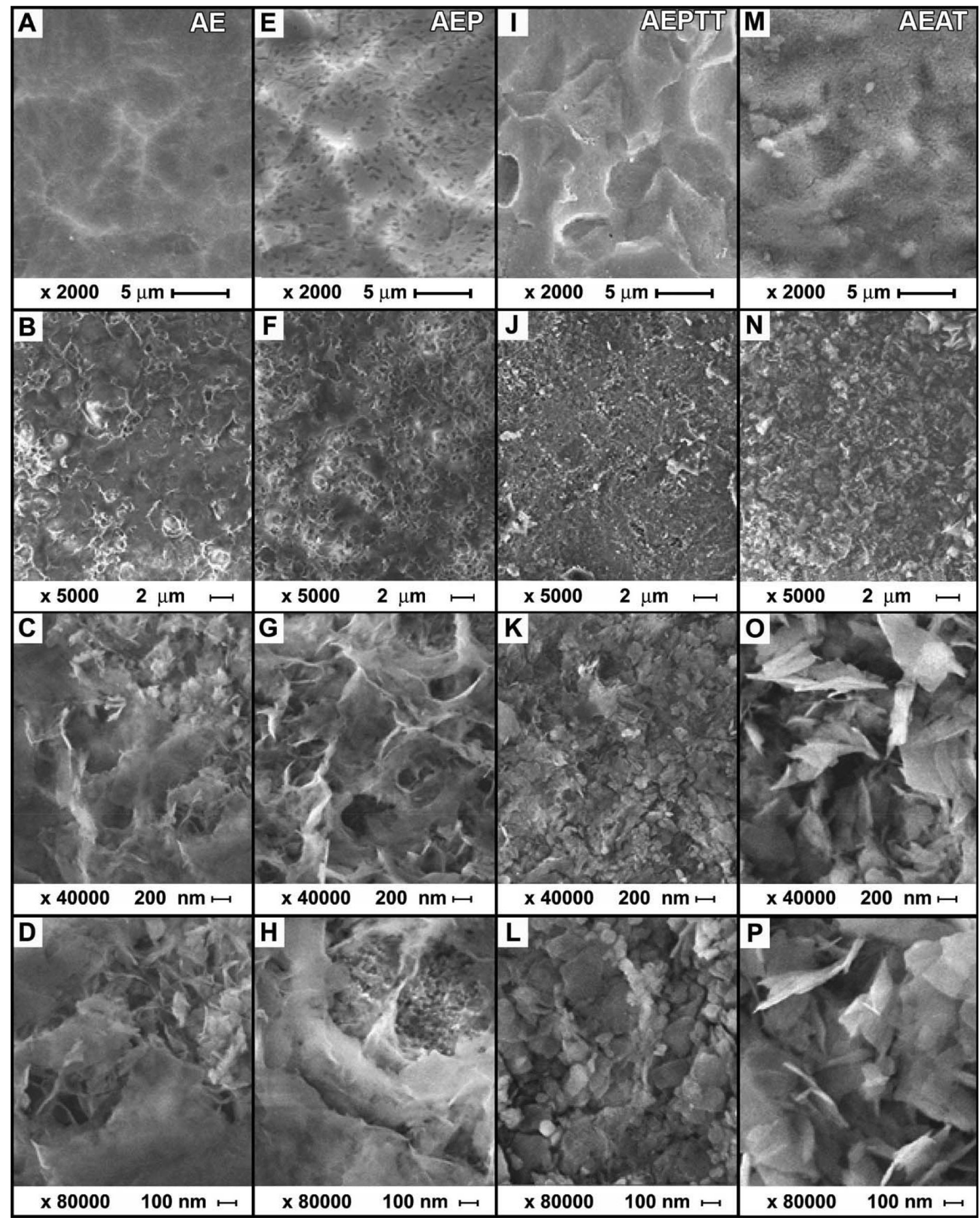

Figure 4. SEM images of the surface modification on titanium $(A, E, I, M)$ and apatite layers obtained on titanium $(B, C, D, F, G, H, J, K, L, N, O, P)$ after soaking in SCS for $24 \mathrm{~h}$

by chemical and thermochemical methods. The morphology of the nanoparticles obtained in the solution (globular) differs from the shape of short rods obtained by Han et al..$^{37}$ The combination of nanoparticle size $(34 \pm 15 \mathrm{~nm})$ with the globular shape can result in a high specific surface area, an issue that promotes their bioreactivity.

The morphology and dimensions of the nanoparticles obtained in solution and on the coatings formed on the surface activated by AEPTT variant were similar. However, the high-magnification micrographs of dense areas (AE, AEP and AEAT) do not clearly reveal the formation of nanoparticles in the surface (Figure $4 \mathrm{C}, \mathrm{D}$, $\mathrm{G}, \mathrm{H}, \mathrm{O}$ and $\mathrm{P}$ ). The formation of nanoparticles with plate-like shape agrees with the results of different works using supersaturated calcification solution (SCS) and some variants of $\mathrm{SBF}^{38}$ The presence of these two morphologies in HA nanoparticles can be explained by the intervention of two nucleation mechanisms in their formation. Particles showing a globular shape are generated by a heterogeneous 

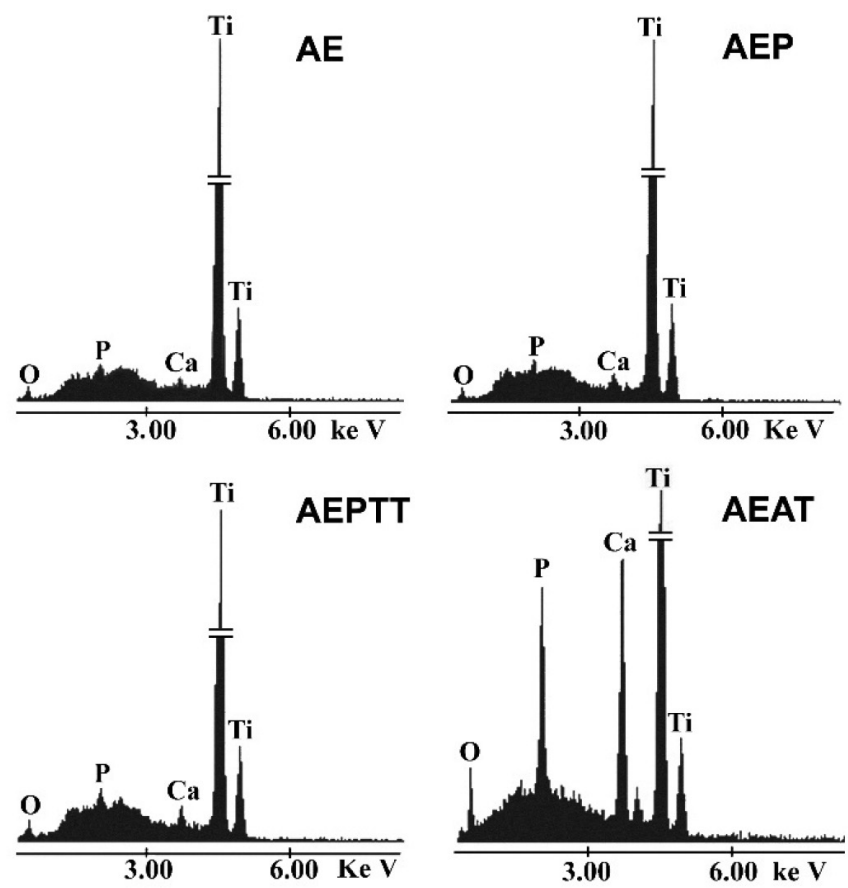

Figure 5. EDX spectra of the surface of the apatite layers obtained on titanium soaked in SCS for $24 \mathrm{~h}$

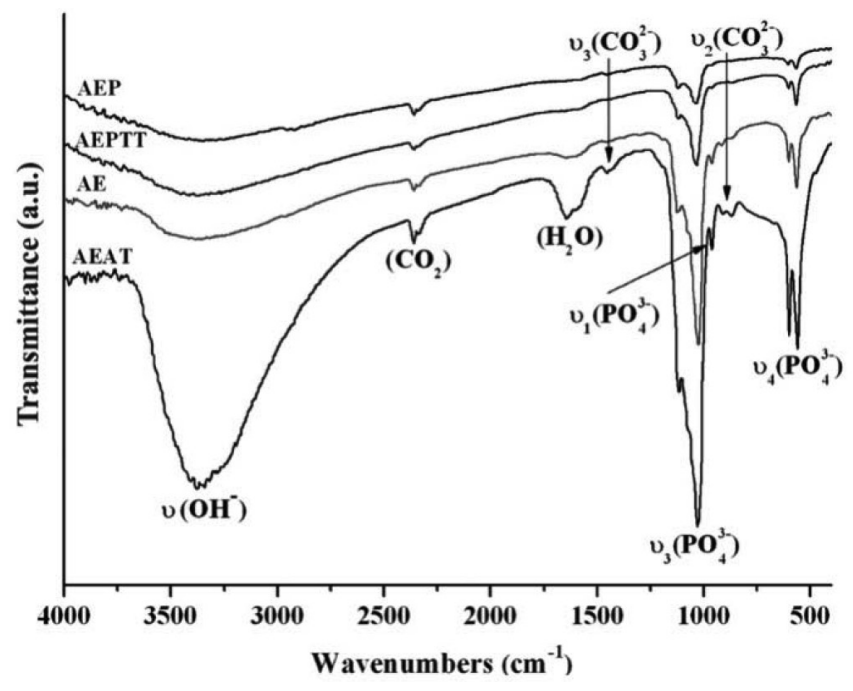

Figure 6. FTIR spectra of apatite layers obtained on titanium soaked in SCS for $24 \mathrm{~h}$

nucleation rate while those with a plate-like shape are formed by a homogeneous nucleation. Both processes probably occurred at the end of precipitation (end of stage 2, Figure 1) as a result of low ionic concentration in the solution.

Micrographs of apatite coatings deposited on the four surfaces studied showed no cracks (Figure 4 A, E, I and M), a common defect reported in coatings formed in solutions with high concentrations of calcium and phosphate ions. ${ }^{19,26,27}$ The absence of cracks in the coating should have a positive impact on their mechanical performance.

FTIR analysis reveals that the coatings obtained on titanium and the nanoparticles formed in solution must be constituted by apatite crystals, a result confirmed by XRD. In addition, EDX tests confirm that the coatings are formed by calcium, phosphorus and oxygen. The presence of the maximum intensity peak at $2=25.74^{\circ}$ is attributed to a preferential orientation in the $c$-axis (diffraction plane 002) of

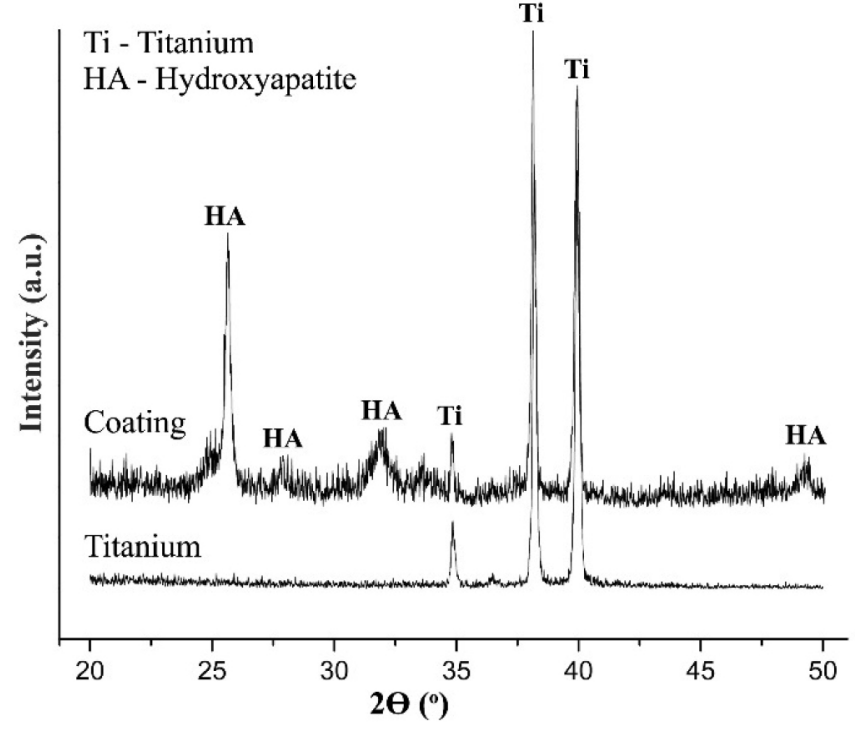

Figure 7. XRD patterns of titanium substrate and apatite coating formed on titanium (AEPTT) after soaking in SCS for $24 \mathrm{~h}$

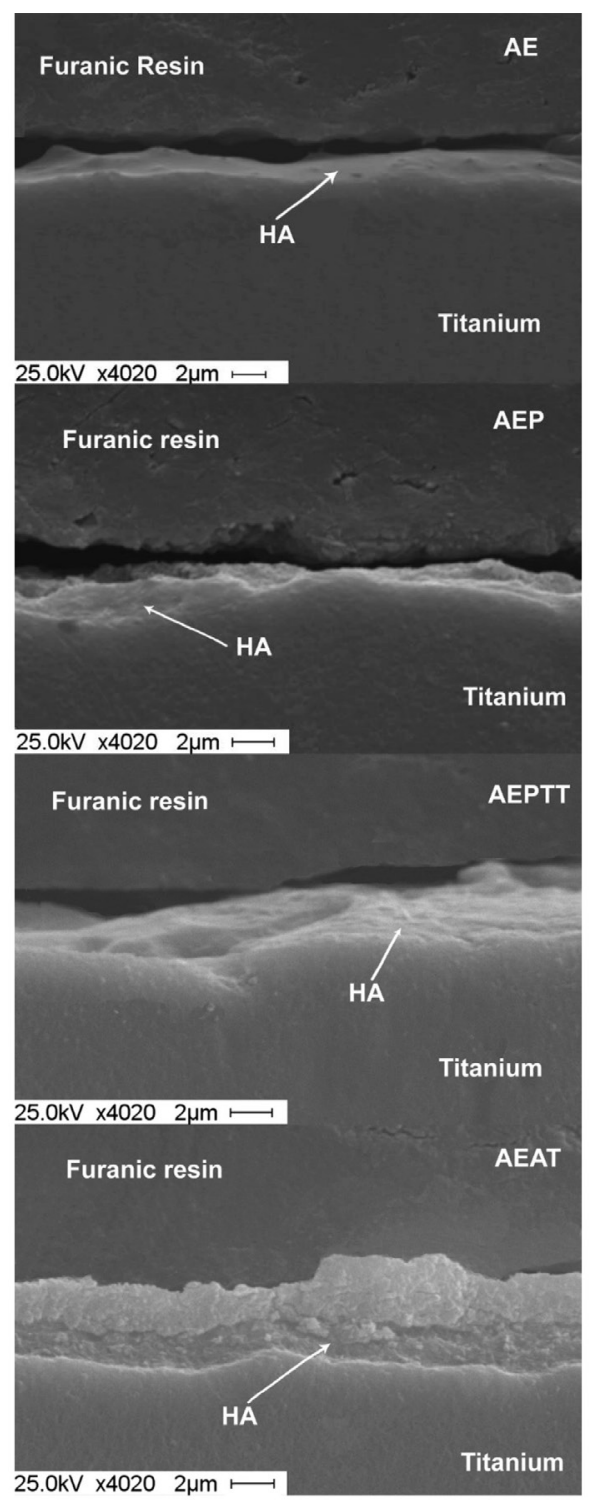

Figure 8. Cross-section micrographs (SEM) of the coatings obtained on titanium soaked in SCS for $24 \mathrm{~h}$ 
the crystals and it was previously reported by $\mathrm{Li}$ and Muller. ${ }^{21,39}$ The sharp peaks observed in the XRD pattern confirm that the coatings are formed of HA with a crystalline structure. This result must be related to the low content of $\mathrm{NaHCO}_{3}$ used in the solution.

Obtaining nanostructured crystalline hydroxyapatite should have positive influence on the stability and mechanical properties of the developed coating in vivo. It is known that the cellular response depends on the chemical composition of the substrate, but also on their solubility, crystallinity and microstructure. Previous studies ${ }^{17,40}$ have shown an increase in cell amount and mineralized extracellular matrix on crystalline substrates, compared with amorphous $\mathrm{Ca}-\mathrm{P}$ coatings. This fact was related with the cell-surface interaction. In contrast with crystalline Ca-P coatings, amorphous coatings should be constantly dissolving and re-precipitating, which can decrease the number of cells attached on the surface, and ultimately decrease the bone formation. ${ }^{17}$ The low dissolution rate of crystalline Ca-P coatings might also reduce the risk of implant loosening. Finally, the nanotopography of the obtained coatings should promote the cell response and enhance the osteogenic activity, ${ }^{41}$ which could positively contribute to the implant success.

\section{CONCLUSIONS}

Nanostructured apatite coatings were obtained on titanium plates, activated by four different treatments. The coatings completely cover the treated surfaces in 24 hours. In addition, they were constituted of crystalline hydroxyapatite, showing a combination of dense and high microporosity areas. All layer thicknesses were found between 1 and $5.3 \mu \mathrm{m}$, while the greater layer thickness was obtained with the acid etching and subsequent alkali treatment (AEAT). Furthermore, it was observed the formation of hydroxyapatite nanoparticles with a globular configuration in the solution. The application of the biomimetic method under the above-mentioned conditions allows the formation of a suitable layer of bone-like apatite in a very short time. This fact should extend the use of this method in the coating of implantable devices, with the aim to increase their bioactivity.

\section{ACKNOWLEDGEMENTS}

The authors wish to express their thanks to the Chancellery and the Ministry of Science and Technology of the Republic of Argentina for his contribution to this work through projects FOAR 5714 and CU/08/13. They also thank the National Institute of Industrial Technology (Argentina) and the Center of Biomaterials of the Polytechnic University of Valencia (Spain) for their assistance in conducting the tests.

\section{REFERENCES}

1. Chen, X.; Li, Y.; Du, J.; Hodgson, P. D.; Acta Biomater. 2009, 5, 1808.

2. Ciobanu, G.; Carja, G.; Ciobanu, O.; Sandu, I.; Sandu, A.; Micron 2009, $40,143$.

3. Fleck, C.; Eifler, D.; Int. J. Fatigue 2010, 32, 929.

4. Kodama, A.; Bauer, S.; Komatsu, A.; Asoh, H.; Ono, S.; Schmuki, P.; Acta Biomater. 2009, 5, 2322.

5. Kim, W. G.; Choe, H. C.; Thin Solid Films 2011, 519, 7045.

6. Vanzillotta, P. S.; Sader, M. S.; Bastos, I. N.; Soares, G. A.; Dent. Mater. 2006, 22, 275.

7. Lakstein, D.; Kopelovitch, W.; Barkay, Z.; Acta Biomater. 2009, 5, 2258.

8. Junker, R.; Dimakis, A.; Thoneick, M.; Jansen, J. A.; Clin. Oral Implants. Res. 2009, 20, 185.
9. He, F. M.; Yang, G. L.; Li, Y. N.; Wang, X. X.; Zhao, S. F.; Int. J. Oral Maxillofac. Surg. 2009, 38, 677.

10. Buser, D.; Nydegger, T.; Oxland, T.; Cochran, D. L.; Schenk, R. K.; Hirt, H. P.; Snétivy, D.; Nolte, L. P.; J. Biomed. Mater. Res. 1999, 45, 75.

11. Braceras, I.; De Maeztu, M. A.; Alava, J. I.; Gay-Escoda, C.; Int. J. Oral Maxillofac. Surg. 2009, 38, 274.

12. Le Guehennec, L.; Goyenvalle, E.; Lopez-Heredia, M.-A.; Weiss, P.; Amouriq, Y.; Layrolle, P.; Clin. Oral Implants Res. 2008, 19, 1103.

13. Yu, X.; Wei, M.; J. Biomater. Nanobiotechnol. 2011, 2, 28.

14. Leonor, I.; Alves, C.; Azevedo, H. S.; Reis, R.; Mater. Sci. Eng., C 2009, 29, 913.

15. Habibovic, P.; Barrère, F.; De Groot, K.; In Learning from Nature How to Design New Implantable Biomaterialsis: From Biomineralization Fundamentals to Biomimetic Materials and Processing Routes; Springer: 2005, p 105.

16. Zheng, C. Y.; Li, S. J.; Tao, X. J.; Hao, Y. L.; Yang, R.; Zhang, L.; Mater. Sci. Eng., C 2007, 27, 824.

17. Dekker, R. J.; de Bruijn, J. D.; Stigter, M.; Barrere, F.; Layrolle, P.; van Blitterswijk, C. A.; Biomaterials 2005, 26, 5231.

18. Nagano, M.; Nakamura, T.; Kokubo, T.; Tanahashi, M.; Ogawa, M.; Biomaterials 1996, 17, 1771.

19. Barrère, F.; Ph.D. thesis, University of Twente, Netherlands, 2002.

20. Habibovic, P.; Li, J.; van der Valk, C. M.; Meijer, G.; Layrolle, P.; van Blitterswijk, C. A.; de Groot, K.; Biomaterials 2005, 26, 23.

21. Li, F.; Feng, Q. L.; Cui, F. Z.; Li, H. D.; Schubert, H.; Surf. Coat. Technol. 2002, 154, 88.

22. Mihranyan, A.; Forsgren, J.; Strømme, M.; Engqvist, H.; Langmuir 2009, 25, 1292.

23. Song, W. H.; Jun, Y. K.; Han, Y.; Hong, S. H.; Biomaterials 2004, 25, 3341 .

24. Lin, D.-Y.; Wang, X.-X., Colloids Surf. B 2011, 82, 637.

25. Barrere, F.; van Blitterswijk, C. A.; de Groot, K.; Layrolle, P.; Biomaterials 2002, 23, 2211.

26. Chen, X.; Li, Y.; Hodgson, P. D.; Wen, C.; Mater. Sci. Eng., C 2009, 29, 165.

27. Pasinli, A.; Yuksel, M.; Celik, E.; Sener, S.; Tas, A. C.; Acta Biomater. 2010, 6, 2282.

28. Qu, H.; Wei, M.; J. Biomed. Mater. Res., B 2008, 87, 204.

29. Yoneyama, Y.; Matsuno, T.; Hashimoto, Y.; Satoh, T.; Dent. Mater. 2013 , $32,115$.

30. Wang, X. X.; Hayakawa, S.; Tsuru, K.; Osaka, A.; J. Biomed. Mater. Res. 2001, 54, 172.

31. Karthega, M.; Nagarajan, S.; Rajendran, N.; Electrochim. Acta 2010, 55 2201

32. Daw, A. E.; Kazi, H. A. A.; Colombo, J. S.; Rowe, W. G.; Williams, D. W.; Waddington, R. J.; Thomas, W.; Moseley, R. J. Biomater. Appl. 2013, $1,17$.

33. Yang, W.; Huang, H.; Thin Solid Films 2010, 518, 7545.

34. Jonasova, L.; Muller, F. A.; Helebrant, A.; Strnad, J.; Greil, P.; Biomaterials 2004, 25, 1187.

35. Kizuki, T.; Takadama, H.; Matsushita, T.; Nakamura, T.; Kokubo, T.; Acta Biomater. 2010, 6, 2836.

36. Rakngarm, A.; Miyashita, Y.; Mutoh, Y.; J. Mater. Sci.: Mater. Med. 2008, 19, 1953.

37. Han, Y.; Wang, X.; Li, S.; J. Nanopart. Res. 2009, 11, 1235.

38. Lu, X.; Zhao, Z.; Leng, Y.; Mater. Sci. Eng., C 2007, 27, 700.

39. Muller, F. A.; Muller, L.; Caillard, D.; Conforto, E.; J. Cryst. Growth 2007, 304, 464 .

40. Chou, L.; Marek, B; Wagner, W.R; Biomaterials 1999, 20, 977.

41. Yi, J.-H.; Bernard, C.; Variola, F.; Zalzal, S.F.; Wuest, J.D.; Rosei, F; Nanci, A.; Surf. Sci. 2006, 600, 4613. 